\title{
EFFECTS OF ELEVATED PLATFORM AND ROBOTIC VEHICLE ON BROILER PRODUCTION, WELFARE, AND HOUSING ENVIRONMENT
}

\author{
X. Yang, X. Huo, G. Li, J. L. Purswell, G. T. Tabler, \\ G. D. Chesser, C. L. Magee, Y. Zhao
}

\begin{abstract}
HighLIGHTS
- Using an elevated platform with a manure catcher reduced litter moisture content and ammonia concentration.

- A robotic vehicle encouraged bird movement and use of the elevated platform.

- Using the elevated platform and robotic vehicle jointly improved broiler paw quality and plumage cleanliness.
\end{abstract}

\begin{abstract}
Elevated platform (EP) and robotic vehicle (RV) are two emerging systems aiming to improve environment enrichment and bird activity in broiler housing systems. However, the impacts of these systems on broiler production, welfare, and housing environment have not been evaluated. The objective of this study was to evaluate the effects of using EP and $R V$ individually or jointly on broiler feed conversion ratio (FCR), litter moisture content (LMC), ammonia ( $\mathrm{NH}_{3}$ ) concentration, gait score (GS), paw quality (PQ), plumage cleanliness (PC), and bird activity index (AI). Broilers were reared for eight-week production cycles. Four experimental rooms (54 birds room ${ }^{-1}$ ) were randomly assigned four treatments: EP only, $R V$ only, $E P$ and $R V(E P+R V)$, and neither EP nor $R V(C t r l)$. Broiler GS, $P Q$, and PC were assessed following welfare protocols. Bird AI was determined through image processing. The experiment was repeated three times. The results showed that overall $F C R$ values were 1.806 for $E P, 1.804$ for $R V, 1.797$ for $E P+R V$, and 1.791 for Ctrl. The normalized LMC values were $23.2 \% \pm 4.1 \%$ for $E P, 32.8 \% \pm 4.1 \%$ for $R V, 23.4 \% \pm 2.5 \%$ for $E P+R V$, and $35.7 \% \pm 7.0 \%$ for Ctrl over the eight-week production cycles. $\mathrm{NH}_{3}$ concentrations were $40 \%$ lower in the rooms with EP than in the rooms without EP at the end of the production cycle. Broilers had better PQ in the rooms with EP than in the rooms without EP. Broiler PC seemed better in the rooms with $R V$ compared to those without $R V$. Operation of $R V$ increased bird AI; however, the benefits in activity encouragement diminished as the broilers grew. The number of broilers on the EP was higher in the EP+RV rooms than in the EP rooms. It is concluded that using EP and RV together may improve broiler welfare and activity without compromising their production performance.
\end{abstract}

Keywords. Behavior, Broiler, Elevated platform, Robotic vehicle, Welfare.

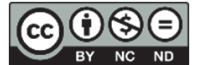

The authors have paid for open access for this article. This work is licensed under a Creative Commons AttributionNonCommercial-NoDerivatives 4.0 International License https://creative commons.org/licenses/by-nc-nd/4.0/

Submitted for review on 22 May 2020 as manuscript number PAFS 14115; approved for publication as a Research Article by the Plant, Animal, \& Facility Systems Community of ASABE on 10 August 2020.

Mention of company or trade names is for description only and does not imply endorsement by the USDA. The USDA is an equal opportunity provider and employer.

The authors are Xiao Yang, Graduate Student, Department of Animal Science, University of Tennessee, Knoxville, Tennessee; Xiaojing Huo, Associate Professor, College of Mechanical and Electrical Engineering, Hebei Agricultural University, Baoding, Hebei Province, China; Guoming Li, Graduate Student, Department of Agricultural and Biological Engineering, Mississippi State University, Mississippi State, Mississippi; Joseph L. Purswell, Agricultural Engineer, USDA-ARS Poultry Research Unit, Starkville, Mississippi; George T. Tabler, Extension Professor, Department of Poultry Science, and Gary D. Chesser, Assistant Professor, Department of Agricultural and Biological Engineering, Mississippi State University, Mississippi State, Mississippi; Christopher L. Magee, Veterinary Medical Officer, USDA-ARS Poultry Research Unit, Starkville, Mississippi; and Yang Zhao, Assistant Professor, Department of Animal Science, University of Tennessee, Knoxville, Tennessee. Corresponding author: Yang Zhao, 2506 River Drive, Knoxville, TN 37996; phone: 865974-6466; e-mail: yzhao@utk.edu.

\section{I} $\mathrm{n}$ the U.S., broiler chickens are raised in floor housing systems. While floor systems have been used for years, the living conditions of broilers are increasingly questioned with current public concerns about farm animal welfare. To address these concerns, animal welfare groups have been progressively promoting environmental enrichment in broiler housing. This movement has resulted in an increasing number of chain restaurants and retailers sourcing poultry meat from producers with higher animal welfare standards. As such, broiler producers are striving to improve their production environments to meet public demands; however, they are facing challenges in multiple dimensions.

Examples of major challenges related to the broiler production environment include poor litter and air quality, barren environmental complexity, and subpar animal welfare and health. Broilers are commonly kept in large flocks in the houses, where litter moisture content gradually builds up as the birds grow. High litter moisture content may result in elevated ammonia $\left(\mathrm{NH}_{3}\right)$ concentration (Chai et al., 2018). Occupational safety and health agencies have recommended 
that the $8 \mathrm{~h}$ time-weighted average (TWA) $\mathrm{NH}_{3}$ level not exceed 25 ppm (NIOSH, 2005); however, $\mathrm{NH}_{3}$ concentrations may exceed the TWA level in commercial broiler houses in the late phases of production cycles (Miles et al., 2004). Many studies have shown that high $\mathrm{NH}_{3}$ concentrations compromise the welfare and health of both caretakers and broilers (Kristensen and Wathes, 2000; Moore et al., 1999; Olanrewaju et al., 2007; Reece et al., 1981). High litter moisture content can also increase the incidence of broiler footpad dermatitis (FPD) and promote growth of pathogenic microorganisms (Dunlop et al., 2016; Kyvsgaard et al., 2013). Plumage quality is also negatively affected by poor litter quality (Jong et al., 2014). Most broiler houses only provide basic resources, such as feeders and drinkers, with few environmental enrichments. Because of the barren environmental complexity, animal welfare groups promote a number of enrichments to establish a welfare standard for broiler production environments. For instance, the Global Animal Partnership (GAP) has proposed a five-step program that requires broiler housing to apply more enrichments to qualify for a higher welfare rating. However, it remains unclear whether and to what extent such enrichments improve broiler welfare and environment.

Elevated platform (EP) is one of the GAP-approved enrichments to accommodate the behavior of broilers. Compared to a traditional bar perch, an EP with ramps is easier for broilers to access at different bird ages and stocking densities (Pettit-riley and Estevez, 2001). Norring et al. (2016) reported that EP could improve bird leg health and walking ability. However, using EP alone did not improve bird activity, which is a critical parameter of animal welfare. Some poultry robots have been developed and commercialized to stimulate bird activity (Tibot Technologies, Brittany, France). Poultry robots may also have potential to increase the spatial awareness of broilers, thus encouraging their use of EP. However, the benefits of applying EP and RV jointly for animal welfare and environmental improvement in broiler production have never been scientifically addressed.

The objective of this study was to evaluate the effects of using an elevated platform and robotic vehicle individually and jointly on broiler production performance, $\mathrm{NH}_{3}$ concentration, litter moisture content (LMC), gait score (GS), paw quality (PQ), plumage cleanliness (PC), and activity. A removable manure catcher was installed under the platform to collect manure dropping from the broilers standing on the platform. This additional component is expected to reduce the litter moisture content and indoor $\mathrm{NH}_{3}$ concentration by removing part of room-level manure production on a regular basis.

\section{MATERIALS AND METHODS BIRD HUSBANDRY}

Four experimental rooms were used, each measuring 3.8 $\mathrm{m} \mathrm{L} \times 1.5 \mathrm{~m} \mathrm{~W} \times 2.1 \mathrm{~m} \mathrm{H}$. Six nipple drinkers (nine birds per drinker) were installed in each room. Two tube feeders $\left(4.2 \mathrm{~cm} \mathrm{bird}^{-1}\right)$ were used before installation of the EP, and one of the feeders was replaced with an open feed trough $\left(5.2 \mathrm{~cm} \mathrm{bird}^{-1}\right)$ on the EP after installation at week 3. Litter was collected from a commercial broiler house, mixed well, and placed on the floor at about $10 \mathrm{~cm}$ depth. A total of 216 Ross 708 chicks were procured from a commercial hatchery and equally assigned to the four experimental rooms (54 birds room $^{-1}$, male:female ratio $\left.=50: 50\right)$. Vaccination and feeding programs (4-phase) followed typical commercial practice. Feed and water were provided ad libitum. A commercial-type corn-soy diet (Dozier et al., 2007), formulated to meet or exceed the requirements of the National Research Council (NRC, 1994), was provided. The birds were kept in the experimental rooms from one day old to 8 weeks of age. Dead birds were removed from the rooms without replacement. Room temperature was maintained at approximately $32^{\circ} \mathrm{C}$ at the start of experiment and was reduced as the birds grew, with a final temperature set point of $22^{\circ} \mathrm{C}$ on day 38 and thereafter. The ventilation rates in all rooms were the same. The lighting schedule was 23L:1D at 30 lux from day 1 to day 7, 20L:4D at 10 lux from day 8 to day $27,16 \mathrm{~L}: 8 \mathrm{D}$ at 5 lux from day 28 to day 53, and 23L:1D at 5 lux from day 54 to day 56 . All experimental procedures were approved by the USDA-ARS institutional animal care and use committee at Mississippi State, Mississippi.

\section{Elevated Platform (EP)}

The EP (fig. 1) was built with wood frames and plastic mesh $(1 \mathrm{~cm} \times 1 \mathrm{~cm}$ hole size $)$. The dimensions of the horizontal section were $120 \mathrm{~cm} \mathrm{~L} \times 60 \mathrm{~cm} \mathrm{~W} \times 15 \mathrm{~cm} \mathrm{H}$. Two $15^{\circ}$ ramps were attached to the sides of the horizontal section, allowing birds access to the platform from both sides. An L-shaped feed trough was installed on the EP to provide additional feed and encourage more broilers to use the EP. Manure defecated by birds standing on the EP was collected with a removable manure catcher and cleaned out every two to three days (three times per week).

\section{ROBOTIC VEHICLE (RV)}

A variable-speed RV (Lynxmotion Aluminum A4WD1, Lynxmotion Inc., Mirabel, QC, Canada) with a remote controller (Spektrum DXe Transmitter System with AR620 Receiver, Horizon Hobby Inc., Champaign, Ill.) was used. The overall dimensions of the RV including the caterpillar track were $32 \mathrm{~cm} \mathrm{~L} \times 24 \mathrm{~cm} \mathrm{~W} \times 10 \mathrm{~cm} \mathrm{H}$. The speed of the RV was adjustable with a maximum of $0.8 \mathrm{~m} \mathrm{~s}^{-1}$. The payload of the $\mathrm{RV}$ was $2.3 \mathrm{~kg}$.

\section{EXPERIMENTAL DESIGN}

Each experimental room was randomly assigned one of four treatments (table 1): elevated platform only (EP), robotic vehicle only (RV), both EP and RV (EP+RV), and neither EP nor RV (control). Starting from week 2, the RV was operated four times a day. The four operations, each lasting $10 \mathrm{~min}$, were performed within $2 \mathrm{~h}$. The RV roamed on the litter floor at a speed of $\sim 0.2 \mathrm{~m} \mathrm{~s}^{-1}$. The EP was installed at the end of week 2 to enhance bird safety. The RV ran only in the open litter areas and not on the EP. The experiment was repeated three times. The first trial (replication 1) was conducted during August to October 2018, and the second trial (replications 2 and 3 ) was conducted during January to March 2020 (table 1). 

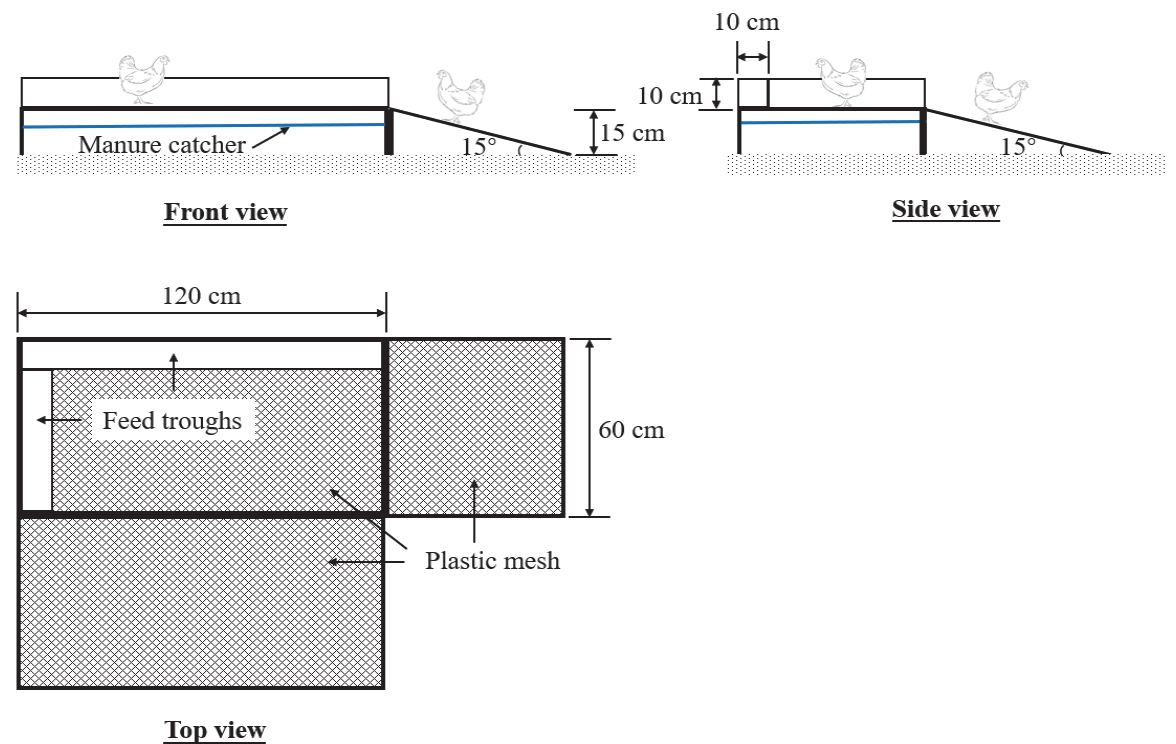

Figure 1. Schematic of elevated platform.

Table 1. Room assignments in two trials of experiment. ${ }^{[a]}$

\begin{tabular}{ccccccccc}
\hline & \multicolumn{7}{c}{ Room Number } \\
\cline { 2 - 8 } Trial & 1 & 2 & 3 & 4 & 5 & 6 & 7 & 8 \\
\hline 1 & $\mathrm{RV}$ & $\mathrm{EP}+\mathrm{RV}$ & $\mathrm{Ctrl}$ & $\mathrm{EP}$ & - & - & - & - \\
2 & $\mathrm{Ctrl}$ & $\mathrm{EP}$ & $\mathrm{RV}$ & $\mathrm{EP}+\mathrm{RV}$ & $\mathrm{EP}+\mathrm{RV}$ & $\mathrm{RV}$ & $\mathrm{EP}$ & $\mathrm{Ctrl}$ \\
\hline [a] & $\mathrm{EP}=$ elevated platform only, RV = robotic vehicle only, EP+RV = both \\
$\mathrm{EP}$ and RV, and Ctrl = neither EP nor RV.
\end{tabular}

\section{MEASUREMENTS}

\section{Production Performance}

Bird body weight and feed intake (FI) were measured by room every two weeks to calculate body weight gain (BWG) and feed conversion ratio (FCR).

\section{Use of Elevated Platform}

The numbers of broilers on the EP before $(6: 00 \mathrm{~h})$, during, and after $(12: 00 \mathrm{~h})$ the RV operation period were counted manually (one day per week, 30 min per day, and 10 min per period) using 10 min videos that were exported as images (1 s per frame). Birds on the EP in each image were counted to track the variation in bird number on the EP within the time period. The final number was the average of 600 counting mumbers. A broiler was considered on the EP only when it was standing or sitting on the platform with both feet. Use of the EP was expressed as the percentage of broilers on the platform.

\section{Litter Moisture Content}

Litter moisture content (LMC) was determined in the experimental rooms every two weeks. In each room, three litter samples were collected at different locations in the open litter area, and three additional samples were collected underneath the EP in the rooms with EP. Each sample (about 40 g) was a composite of three subsamples collected within a $10 \mathrm{~cm} \times 10 \mathrm{~cm}$ area. All subsamples were collected from the surface layer at 0 to $4 \mathrm{~cm}$ depth. The litter samples were weighed with an analytical balance ( $0.01 \mathrm{~g}$ precision) immediately after being fully mixed by shaking, and again after being oven-dried at $105^{\circ} \mathrm{C}$ for $24 \mathrm{~h}$. The normalized $\mathrm{LMC}$, which represents the room-level LMC by assuming homogeneous mixing of litter in the open litter area and underneath the EP (including the area underneath the ramps), was calculated using equation 1:

$$
\mathrm{LMC}_{\text {norm }}=\frac{\mathrm{LMC}_{o p} \times S_{o p}+\mathrm{LMC}_{E P} \times S_{E P}}{S_{\text {room }}}
$$

where

$$
\begin{aligned}
& \mathrm{LMC}_{\text {norm }}=\text { normalized litter moisture content }(\%) \\
& \mathrm{LMC}_{o p}=\text { litter moisture content of open litter area }(\%) \\
& \mathrm{LMC}_{E P}=\text { litter moisture content underneath EP }(\%) \\
& S_{o p}=\text { area of open litter area }\left(\mathrm{m}^{2}\right) \\
& S_{E P}=\text { area of EP }\left(\mathrm{m}^{2}\right) \\
& S_{\text {room }}=\text { area of experimental room }\left(S_{o p}+S_{E P}, \mathrm{~m}^{2}\right) .
\end{aligned}
$$

\section{Ammonia Concentration}

Concentrations of $\mathrm{NH}_{3}$ in the experimental rooms and in the air supply plenum were monitored continuously with a multi-gas analyzer (model 1412, Innova AirTech Instruments, Ballerup, Denmark) (Purswell et al., 2018). The sampling cycle was set to $30 \mathrm{~s}$. To ensure accurate measurement of the $\mathrm{NH}_{3}$ concentrations, considering the response time of the analyzer, each room was sampled for $12 \mathrm{~min}$, with the first $11 \mathrm{~min}$ for stabilization and the last minute for measurement. This sequential measurement yielded hourly data of the $\mathrm{NH}_{3}$ concentrations. A measurement and control data logger (CR1000, Campbell Scientific, Logan, Utah) was used to switch among the sampling tunnels and record the data.

\section{Welfare Assessment}

Scores of GS, PQ, and PC for 16 broilers ( 8 males and 8 females) were determined in each experimental room at 4 and 8 weeks of age. Assessment procedures described by the Welfare Quality Assessment Protocol (Welfare Quality, 2009) and the American Association of Avian Pathologists (AAAP) were followed. For GS, broilers were assigned a score from 0 to 2 , where $0=$ able to walk at least $1.5 \mathrm{~m}$ with a balanced gait (slightly awkward but with no effect on accessing resources), $1=$ able to walk over $1.5 \mathrm{~m}$ with a clear limp, and 2 = not able to walk $1.5 \mathrm{~m}$. For PQ, broilers were 
assigned a score from 0 to 2 based on lesion area caused by FPD, where $0=$ no lesion or slight discoloration of the skin, $1=$ lesion area $<50 \%$ of the footpad area, and $2=$ lesion area $\geq 50 \%$ of the footpad area (including lesions on the toes). The PC of broilers was scored from 0 to 3 , where $0=$ white plumage without caked dirt, $1=$ light brown plumage without caked dirt, 2 = brown plumage with small caked dirt, and 3 $=$ dark plumage with large caked dirt.

\section{Broiler Activity}

Bird activity index (AI) before, during, and after the RV operation period was determined via image processing in MATLAB (ver. 2018b, The MathWorks, Natick, Mass.). Cameras (NHD-850, Swann Communications, Santa Fe Springs, Cal.) were mounted to the ceiling at the same height used to record the EP videos. The AI videos were exported as RGB images ( 3 frames per second) and then converted to grayscale for further analysis. The same $900 \times 700$ pixel areas in consecutive grayscale images were then cropped out (figs. $2 \mathrm{a}$ and $2 \mathrm{a}^{\prime}$ ). The total bird pixels within the croppedout area (figs. $2 b$ and $2 b^{\prime}$ ) and the pixel changes between two consecutive images (fig. 2c) were segmented and quantified. Broiler AI was calculated as the ratio of bird pixel changes to total bird pixels.

\section{Data Preparation and Statistical Analysis}

Feed consumption of mortalities was included in the calculation of FCR. The treatment effects on BW, BWG, FI, and FCR were tested by age. The percentage of broilers using the EP was determined. The effects of RV operation on the use of EP at different time periods (before, during, and after RV operation) were tested. The age effects of the use of EP were also tested. The $\mathrm{NH}_{3}$ level was summarized as the daily average $\mathrm{NH}_{3}$ concentration of rooms with or without EP. Weekly average $\mathrm{NH}_{3}$ concentration was used for multiple comparisons. Data on welfare assessment (GS, PQ, and $\mathrm{PC}$ ) were converted into the percentage of broilers at each score level in each room. The average scores for each room were calculated as well. The treatment effects on broiler welfare were tested separately in week 4 and week 8 . For broiler AI, treatment effects were tested on overall AI and $\mathrm{AI}$ at different time periods (before, during, and after RV operation). Due to the limited sample size, a non-parametric test (Kruskal-Wallis test) was used to analyze the overall welfare scores. The rest of the data were analyzed as a completely randomized design using the PROC MIXED procedure in SAS (ver. 9.4, SAS Institute, Cary, N.C.). Significant difference of multiple comparisons of group means was defined as $\mathrm{p}<0.05$.

\section{RESULTS AND DISCUSSION Production Performance}

Table 2 shows the BW, BWG, FI, and FCR summarized at weeks $2,4,6$, and 8 in the four experimental rooms. In general, BW, BWG, FI, and FCR in the four rooms increased as the birds grew. No significant difference in BW, BWG, or FI was found among the treatments and control. These results were similar to a previous study by Bailie et al. (2018) in which platforms had no effect on the slaughter weight of broilers. Significantly higher FCR was observed in the Ctrl rooms compared with the $\mathrm{RV}(\mathrm{p}=0.019)$ and $\mathrm{EP}+\mathrm{RV}(\mathrm{p}=$ 0.049 ) rooms by week 2 . However, no significant differences in FCR were observed among the treatment and control rooms later on. This indicates that the application of EP or RV had no adverse effect on broiler production performance.

\section{Use of Elevated Platform}

No significant difference in the percentage of broilers on the EP was observed before and after RV operation. However, during RV operation, the percentage of birds on the platform was significantly $(\mathrm{p}<0.0001)$ higher in the EP+RV $(47.6 \%)$ rooms than in the EP $(30.2 \%)$ rooms (fig. $3 a)$. Over the flock, the average percentage of broilers on the platform was significantly $(\mathrm{p}<0.0001)$ higher in the EP+RV $(37.2 \%)$ rooms than in the EP (31.2\%) rooms (fig. $3 b)$. This shows that RV operation can encourage more birds to use the EP.

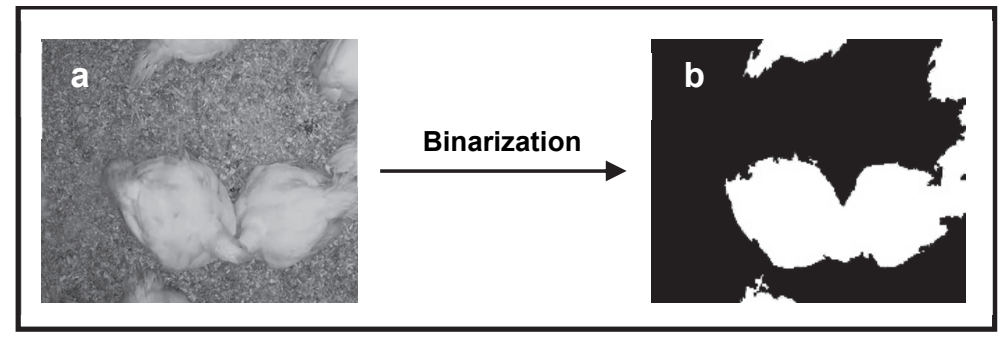

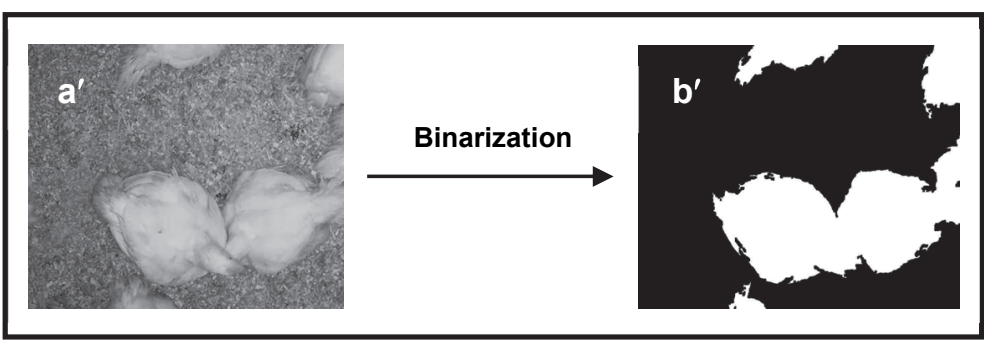
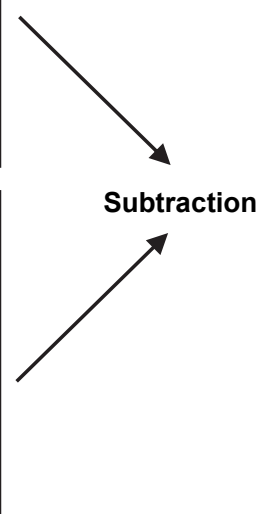

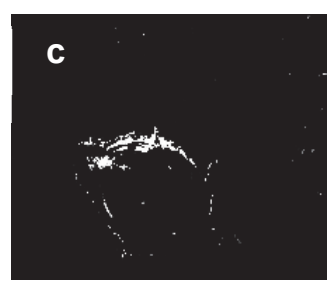

Figure 2. Image processing for bird activity index: (a) current cropped-out grayscale image, (a') successive cropped-out grayscale image, (b) current binary image showing bird pixels in white, $\left(b^{\prime}\right)$ successive binary image showing bird pixels in white, and (c) binary image showing changes in bird pixels in the two consecutive images $\left(b^{\prime}-b\right)$. 
Table 2. Body weight, body weight gain, feed intake, and feed conversion ratio at weeks $2,4,6$, and 8 in the treatment rooms.

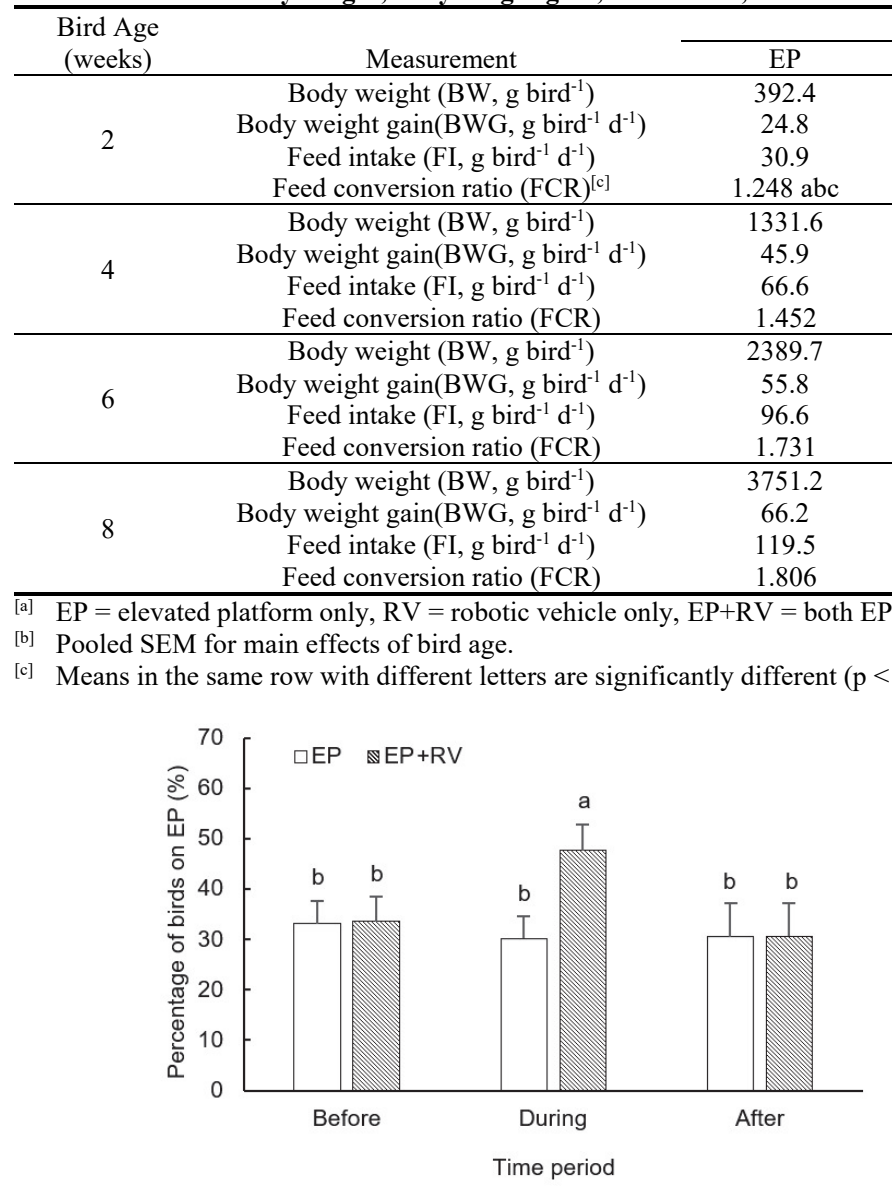

(a)

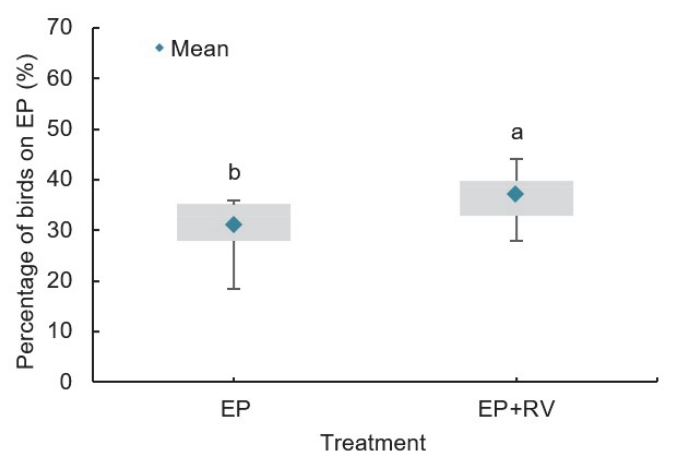

(b)

Figure 3. (a) Percentage (mean \pm SD) of broilers on platform in treatment rooms with elevated platform only (EP) and with EP and robotic vehicle $(\mathrm{EP}+\mathrm{RV})$ before, during, and after robot operation, and (b) average percentage of broilers on platform in EP and EP+RV rooms. Means with different letters are significantly different $(p<0.05)$.

The percentage of broilers using the EP continuously increased from 3 to 5 weeks of age in both the EP $(p=0.0006)$ and $\mathrm{EP}+\mathrm{RV}(\mathrm{p}<0.0001)$ rooms and slightly decreased $(\mathrm{p}>$ 0.05 ) after week 6 (fig. 4). The slight decrease in EP use after week 6 probably occurred because the broilers were larger and there was not enough room for more birds to use the EP. Another factor in reduced EP use by older birds could be their increased body weight, which impeded them from

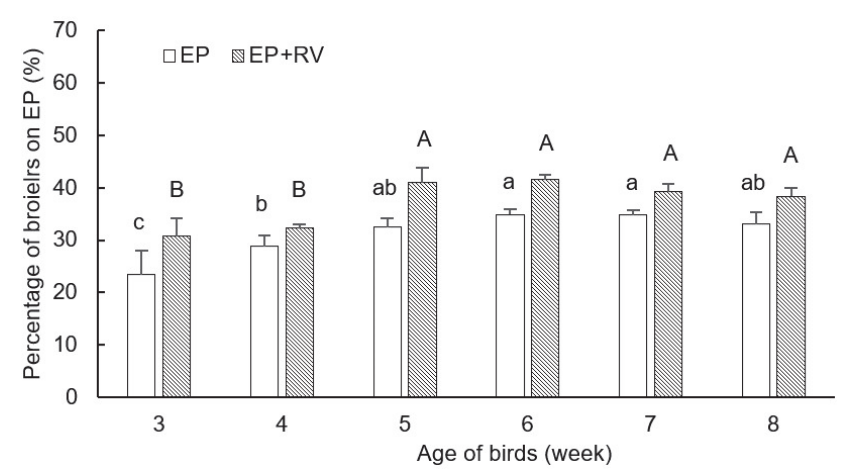

Figure 4. Weekly average percentage (mean \pm SD) of broilers on platform in rooms with elevated platform only (EP) and with both EP and robotic vehicle $(\mathrm{EP}+\mathrm{RV})$. Means with different lowercase letters (for EP treatment) and with different uppercase letters (for EP+RV treatment) are significantly different $(p<0.05)$. climbing. Ventura et al. (2012) and Bailie and O'Connell (2015) reported that the peak activity of broilers occurred at 4 to 5 weeks of age and gradually decreased thereafter. Although the effect of the RV also started to decrease after week 4, based on the AI results, use of the EP was still numerically greater in the EP+RV rooms than in the EP rooms (fig. 4).

\section{LitTer Moisture Content}

Table 3 shows the normalized LMC of the four treatments at different bird ages. No significant difference was observed among the four treatments before the installation of EP (week 3). In week 4, the LMC was significantly lower in the $\mathrm{EP}$ and $\mathrm{EP}+\mathrm{RV}$ rooms than in the $\mathrm{RV}$ rooms $(\mathrm{p}=0.011$ and $\mathrm{p}=0.007$, respectively). In weeks 6 and 8 , the rooms with EP had significantly lower LMC than those without EP ( $p<$ 0.03 for all). These results indicate that EP effectively reduced the increase in LMC. However, Kaukonen et al. (2017) reported that litter condition and quality were not affected by the platform. This conflicting result could be explained by the additional manure catcher that was added underneath the EP in our study. Manure that accumulated on the catcher, as well as under the two ramps, was cleaned out manually three times per week. Assuming that a consistent $30 \%$ of the birds used the platform (see the previous section), 
Table 3. Normalized litter moisture content (LMC) in treatment rooms over the production cycle. Elevated platforms were placed in the EP rooms at the end of week 2 , and the robotic vehicle started operating at the beginning of week 2 .

\begin{tabular}{cccccc}
\hline \multirow{2}{*}{$\begin{array}{c}\text { Bird Age } \\
\text { (weeks) }\end{array}$} & \multicolumn{4}{c}{ Mean Normalized LMC (\%) ${ }^{[\mathrm{a}]}$} & \\
\cline { 2 - 5 } & $\mathrm{EP}$ & $\mathrm{RV}$ & $\mathrm{EP}+\mathrm{RV}$ & $\mathrm{Ctrl}$ & SEM $^{[\mathrm{b}]}$ \\
\hline 0 & 6.5 & 7.0 & 6.4 & 6.9 & 2.1 \\
2 & 14.0 & 14.3 & 13.2 & 13.9 & 3.2 \\
$4^{[\mathrm{c}]}$ & $16.0 \mathrm{bc}$ & $20.6 \mathrm{a}$ & $15.6 \mathrm{c}$ & $18.9 \mathrm{ab}$ & 1.0 \\
$6^{[\mathrm{c}]}$ & $20.5 \mathrm{~b}$ & $29.9 \mathrm{a}$ & $20.9 \mathrm{~b}$ & $27.3 \mathrm{a}$ & 1.3 \\
$8^{[\mathrm{c}]}$ & $23.2 \mathrm{~b}$ & $32.8 \mathrm{a}$ & $23.5 \mathrm{~b}$ & $35.7 \mathrm{a}$ & 2.6 \\
\hline
\end{tabular}

[a] $\mathrm{EP}=$ elevated platform only, $\mathrm{RV}=$ robotic vehicle only, $\mathrm{EP}+\mathrm{RV}=$ both $\mathrm{EP}$ and $\mathrm{RV}$, and $\mathrm{Ctrl}=$ neither EP nor RV.

[b] Pooled SEM for main effects of bird age.

[c] Means with different letters in the same row are significantly different $(\mathrm{p}<0.05)$.

about $1 / 3$ of the manure could be removed from the room, which significantly reduced the LMC. Adding the manure catcher to the EP would inevitably increase the cost of a commercial system. However, such cost could be potentially compensated by a series of benefits, such as reduced $\mathrm{NH}_{3}$ concentration and improved PQ, due to the lower LMC. An economic analysis is thus warranted for commercial production. While this study proved the benefits of using a manure catcher with EP, application of manure catchers at commercial scale would require automated operation, rather than the manual operation in this lab-scale study.

\section{Ammonia ConCEnTRATion}

Daily $\mathrm{NH}_{3}$ concentrations in the rooms with and without EP are shown in figure 5. No significant difference was observed between rooms with and without EP by week 6 . This was likely because the LMC in week 6 was not high enough for a significant increase in $\mathrm{NH}_{3}$. Carr et al. (1990) reported that $\mathrm{NH}_{3}$ volatilization significantly increased when the LMC was higher than $30 \%$. In our study, the LMC in rooms without EP increased to $30 \%$ during weeks 6 to 8 , which is consistent with the time when the $\mathrm{NH}_{3}$ difference was observed. In week 7 , the $\mathrm{NH}_{3}$ level was significantly higher ( $\mathrm{p}$ $=0.002$ ) in rooms without EP than in rooms with EP, and the difference continuously increased until week $8(\mathrm{p}<0.0001)$. This mainly occurred because the manure catcher increased the difference in LMC between rooms with and without EP during the last two weeks.

High LMC can increase the conversion rate of the uric acid in manure to ammonia-N (Sims and Wolf, 1994), thereby leading to higher $\mathrm{NH}_{3}$ volatilization from the manure (Elliott and Collins, 1982; Liu et al., 2007). The $\mathrm{NH}_{3}$ concentration in the non-EP rooms exceeded the NIOSH-recommended threshold ( $25 \mathrm{ppm}$ ) and reached $43 \mathrm{ppm}$ by the end of the flocks. In the EP rooms, the $\mathrm{NH}_{3}$ level was $26 \mathrm{ppm}$, which was $40 \%$ lower than in the non-EP rooms. In commercial broiler production, body weight and FCR are among the critical economic factors affected by elevated $\mathrm{NH}_{3}$. Miles et al. (2004) reported that broilers exposed to 50 or $70 \mathrm{ppm}$ $\mathrm{NH}_{3}$ were significantly lighter than broilers exposed to 0 or 25 ppm in week 4 and week 8 , but no significant difference was observed for FCR. In contrast, Quarles and Caveny (1979) found that neither bird weight nor FCR were affected by 50 ppm $\mathrm{NH}_{3}$ in week 8 . Similar results were obtained in our study, i.e., there was no significant difference in body weight or FCR among the different rooms when the $\mathrm{NH}_{3}$ concentration exceeded $25 \mathrm{ppm}$. In summary, EP with a manure catcher effectively reduced the $\mathrm{NH}_{3}$ concentration in the EP rooms during the last two weeks of the flocks.

\section{Welfare ASSESSMENT}

All broilers had a GS of 0 at weeks 4 and 8 (fig. 6), except for one broiler in an EP room that had a GS of 1 in week 8 (fig. 6b). Over the flocks, more than $99 \%$ broilers scored 0 , which means that the majority of the broilers had good walking ability. However, as a major welfare issue of broilers that may cause economic loss, the prevalence of lameness in commercial houses could be much higher. Previous field research reported that over $90 \%$ of broilers showed at least some degree of lameness between 6 and 7 weeks of age (Kestin et al., 1992). Knowles et al. (2008) also reported that over $27.6 \%$ of birds showed poor locomotion at a mean age of 40 days, and $3.3 \%$ were almost unable to walk. The difference between these results may due to husbandry practices (Edwards and Sorensen, 1987), management, nutrition (Waldenstedt, 2006), and genetic factors (Kestin et al., 1992). In addition, GS assessment mainly relies on human observation and the assessor's interpretation of the protocol, which can lead to subjective results. Comparison of GS results among studies can be difficult, if not impossible, because of inherent human errors and variations in assessment protocols. Therefore, precision production technologies, e.g., motion sensors (Stevenson et al., 2019) and video monitoring systems (Aydin et al.,

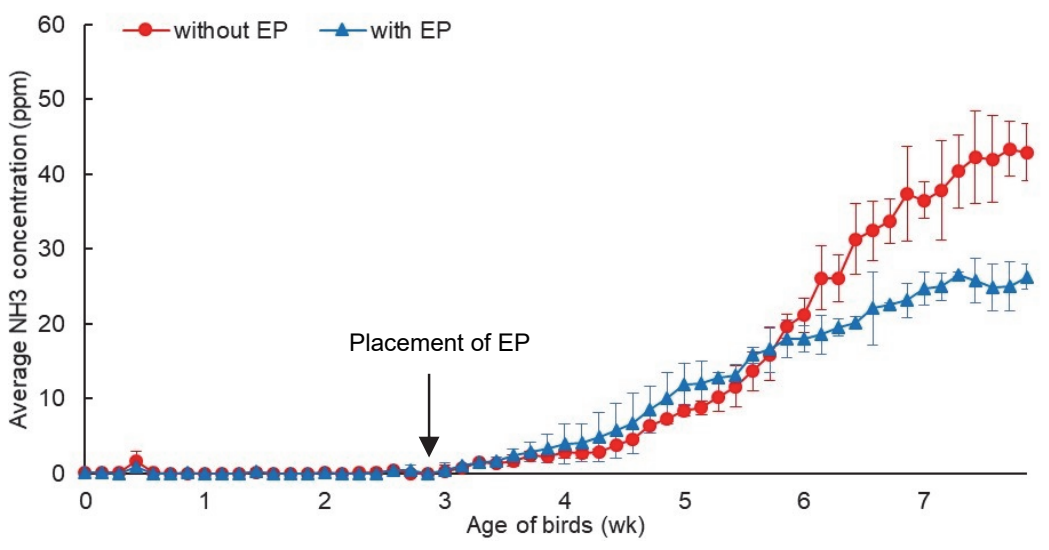

Figure 5. Daily indoor $\mathrm{NH}_{3}$ concentrations (mean $\pm \mathrm{SD}$ ) in rooms with and without EP. 


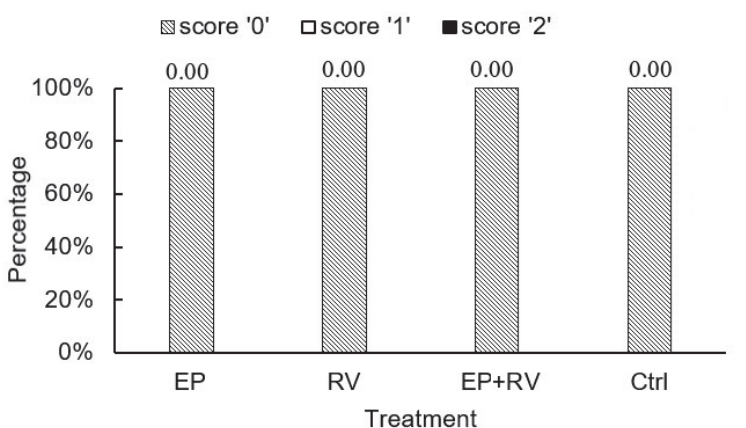

(a) Week 4

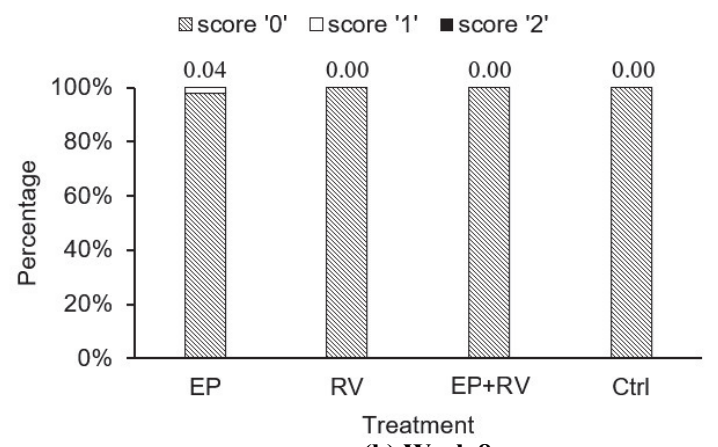

(b) Week 8

Figure 6. Distribution of broiler gait score (GS) in treatment rooms at weeks 4 and 8 . A score of 0 indicates the best walking ability, and a score of 2 indicates the worst walking ability. Numbers above bars are average scores for each treatment.

2010), that can evaluate poultry welfare objectively and precisely are urgently needed.

In week 4, all broilers in the EP and EP+RV rooms had no footpad lesions (PQ score of 0 ), while $4.1 \%$ of broilers in the RV rooms and $6.3 \%$ of broilers in the Ctrl rooms had intermediate (PQ score of 1) or severe (PQ score of 2) lesions (fig. 7a). At week 8, the occurrence of footpad lesions in the EP rooms was still 0, while $12.5 \%$ of broilers in the RV rooms, $6.3 \%$ of broilers in the $\mathrm{EP}+\mathrm{RV}$ rooms, and $6.3 \% \mathrm{pf}$ broilers in the Ctrl rooms had intermediate or severe lesions (PQ score of 1 or 2) (fig. 7b). Previous studies reported very high incidences of footpad lesions caused by FPD. For example, Nakaue et al. (1981) reported that $53 \%$ of birds had FPD by week $7(\mathrm{LMC}=46 \%)$. Allain et al. (2009) found that over $90 \%$ of birds had intermediate and deep FPD. However, a study in northern Europe (Haslam et al., 2007) reported only $11 \%$ prevalence of FPD, which is similar to our results. That same study also showed very high variability, with FPD ranging from $0 \%$ to $71.5 \%$, indicating a high prevalence in some flocks. The cause of FPD is multifactorial and involves genetics, nutrition, environment, and other factors (Shepherd and Fairchild, 1987). Among those factors, LMC appears to be the most important (Jong et al., 2014; Martland, 1985; Shepherd and Fairchild, 1987). The manure catcher reduced LMC, and the EP offered broilers an opportunity to temporarily avoid the litter, which may help decrease the prevalence of FPD.

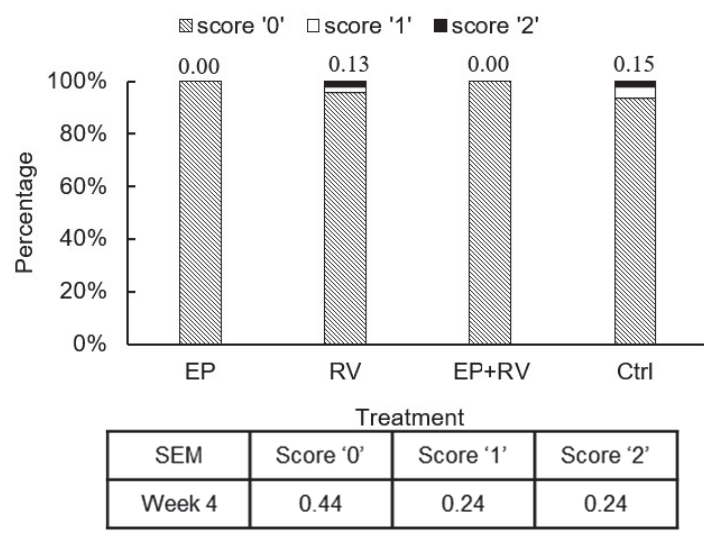

(a) Week 4
Our results showed that the average PQ score was 0.11 in the rooms without EP and only 0.01 in the rooms with EP by the end of the flocks. The increased export of chicken paws to Asia makes FPD a great concern in broiler production. This demand has turned paws into the third most economically important chicken part, accounting for approximately \$280 million in 2008 (Poultry Site, 2009). Lesions caused by FPD degrade paw products and negatively affect the health and welfare of broilers (Haslam et al., 2007). Our EP showed the possibility of improving the PQ scores of broilers. The overall PQ scores were numerically lower for the EP and $\mathrm{EP}+\mathrm{RV}$ rooms than for the Ctrl rooms over the flocks, probably because of the manure catcher and RV operation. Broilers were encouraged by the RV to move to the EP, thereby reducing their contact time with the litter. In addition, exposing the litter to ventilation for a longer period of time may help keep it dry, thereby benefitting bird welfare.

At week 4, 66.7\% of broilers in the EP+RV rooms had a PC score of 0 , while $50 \%$ of broilers in the EP rooms, $54.6 \%$ of broilers in the RV rooms, and $54.2 \%$ of broilers in the Ctrl rooms had a PC score of 0 (fig. 8a). At week 8 , the proportions of broilers with PC scores of 2 or 3 in the EP and $\mathrm{EP}+\mathrm{RV}$ rooms were $25 \%$ and $22.9 \%$, respectively (fig. $8 \mathrm{~b}$ ). However, $31.3 \%$ of broilers in the RV rooms and $58.3 \%$ of broilers in the Ctrl rooms scored 2 or 3 . The most severe plumage condition (PC score of 3 ) was observed only in the EP (8.3\%) and Ctrl (6.3\%) rooms (fig. 8b). In general, PC

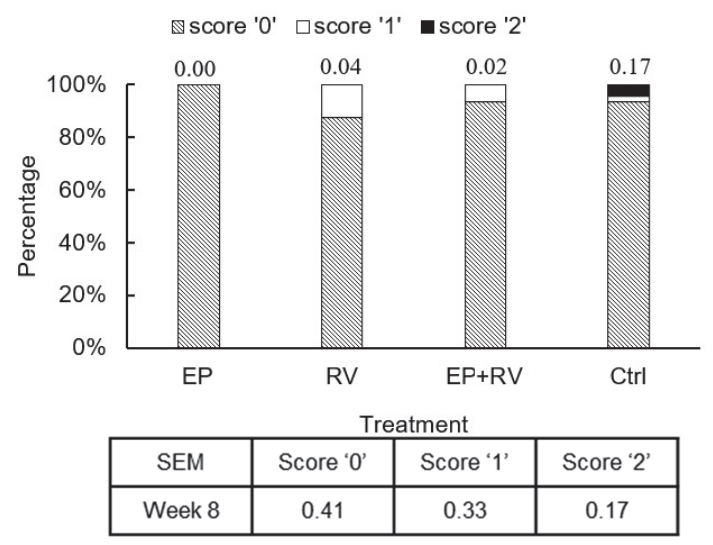

(b) Week 8

Figure 7. Distribution of broiler paw quality (PQ) in treatment rooms at weeks 4 and 8 . A score of 0 indicates the best footpad condition, and a score of 2 indicates the worst footpad condition. Numbers above bars are average scores for each treatment. Pooled SEM data for main effects of PQ score level are listed in the tables. 


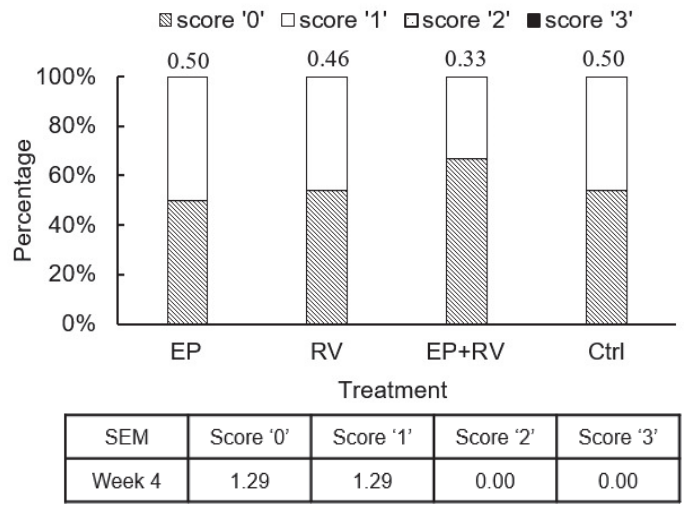

(a) Week 4

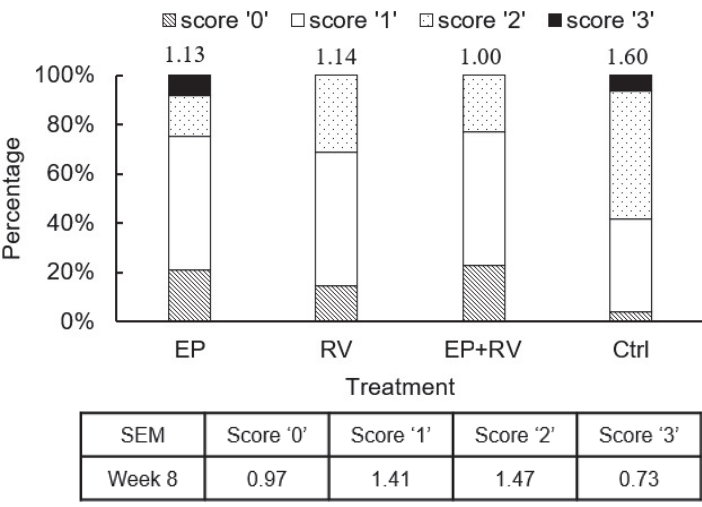

(b) Week 8

Figure 8. Distribution of broiler plumage cleanliness (PC) in treatment rooms at weeks 4 and 8 . A score of 0 indicates the best plumage cleanliness, and a score of 3 indicates the worst plumage cleanliness. Numbers above bars are average scores for each treatment. Pooled SEM data for main effects of PC score level are listed in the tables.

degraded as the broilers grew older, which was mainly due to the increase in LMC (Federici et al., 2016; Jong et al., 2014) and the time the birds spent lying on the floor. Plumage plays a major role in insulating the bodies of birds. Clean and well-covered plumage can protect broilers from moist dirt and skin infections (Stephenson et al., 1960; Welfare Quality, 2009). Plumage can also optimize the energy metabolism and feed efficiency of broilers in cool conditions (Herreid and Kessel, 1967; Leeson and Walsh, 2004). At week 8 , the proportions of broilers that scored 0 were higher in the EP $(20.8 \%)$ and EP+RV $(22.9 \%)$ rooms than in the RV (14.6\%) and Ctrl (4.2\%) rooms (fig. 8b). This may be because the EP provided broilers a cleaner surface on which to rest, which helped to keep their plumage clean. The results also indicate that operation of the RV can contribute to better plumage condition by reducing the contact time of the birds with the litter. The average PC score was numerically lower for the EP+RV rooms (1.00) than for the Ctrl rooms (1.60) at week 8, which indicates the potential of using EP and RV jointly to keep broiler plumage clean.

\section{BROILER ACTIVITY}

In general, broiler AI was significantly higher in the RV and $\mathrm{EP}+\mathrm{RV}$ rooms $(\mathrm{p}=0.003$ and $\mathrm{p}=0.0008)$ than in the Ctrl rooms. Significantly higher broiler AI was also found in the EP+RV rooms $(p=0.017)$ as compared with the EP rooms. During the 40 min RV operation period, broiler AI was significantly higher $(p<0.0001)$ in the RV and $E P+R V$ rooms than in the Ctrl rooms (fig. 9). No significant difference was observed among the four treatments before and after RV operation (fig. 9). Research has shown that increasing environmental complexity may improve activity and thus improve both the physical and psychological well-being of farm animals (Bizeray et al., 2002; Cheal, 1987; Ventura et al., 2010). Elevated structures can increase the spatial awareness of broilers and excite more locomotive behaviors, such
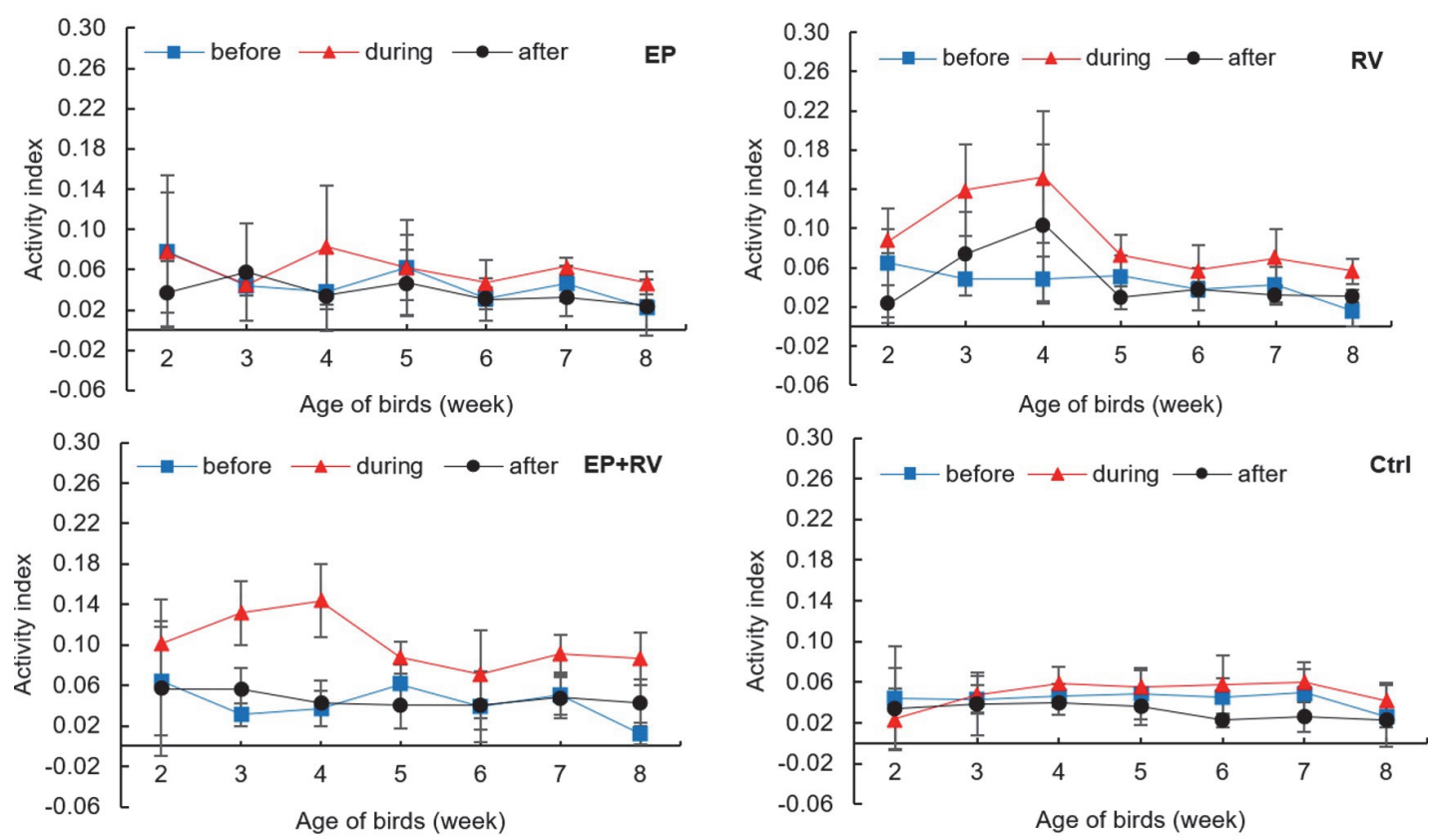

Figure 9. Broiler activity index (AI) in treatment rooms with elevated platform only (EP), robotic vehicle only (RV), both EP and RV (EP+RV), and neither EP nor RV (Ctrl) before, during, and after robot operation. 
jumping and walking up and down the ramps. Several studies (Bailie and O'Connell, 2015; Norring et al., 2016; Rodriguez-Aurrekoetxea et al., 2015) and our results failed to show an increase in bird activity level using only the EP. However, our study showed that combining static (EP) and dynamic (RV) objects may effectively promote broiler activity. Continuous increase in broiler AI was observed in the rooms with RV from week 2 to week 4, although AI started to decrease thereafter. A possible reason for the decrease is that the broilers were adapted to the RV, and thus less avoidant of it, after a few weeks of RV operation. Moreover, the broilers became less active as they grew older and heavier. Parajuli et al. (2018) determined the broiler-RV avoidance distances and reported similar results, i.e., less avoidance of an RV for older broilers. Additional stimulation, such as adding sound or lights to the RV, could be considered to sustain the effect of the RV for encouraging broiler activity.

\section{SUMMARY AND CONCLUSIONS}

In this study, the effects of an elevated platform and robotic vehicle on broiler production, welfare, and housing environment were examined over eight-week production cycles. We conclude that using the elevated platform with the manure catcher reduced litter moisture content and ammonia concentration. The robotic vehicle encouraged bird movement and improved the use of the elevated platform. Using the elevated platform and robotic vehicle jointly improved broiler paw quality and plumage cleanliness.

\section{ACKNOWLEDGEMENTS}

This publication is a joint contribution of the Mississippi Agricultural and Forestry Experiment Station, the USDAARS, and the USDA NIFA Multistate Project under Accession No. 1020090. We thank the assistance provided by staff at the USDA-ARS Poultry Research Unit and the Department of Agricultural and Biological Engineering at Mississippi State University.

\section{REFERENCES}

Allain, V., Mirabito, L., Arnould, C., Colas, M., Le Bouquin, S., Lupo, C., \& Michel, V. (2009). Skin lesions in broiler chickens measured at the slaughterhouse: Relationships between lesions and between their prevalence and rearing factors. British Poultry Sci., 50(4), 407-417. https://doi.org/10.1080/00071660903110901

Aydin, A., Cangar, O., Ozcan, S. E., Bahr, C., \& Berckmans, D. (2010). Application of a fully automatic analysis tool to assess the activity of broiler chickens with different gait scores. Comput. Electron. Agric., 73(2), 194-199. https://doi.org/10.1016/j.compag.2010.05.004

Bailie, C. L., \& O'Connell, N. E. (2015). The influence of providing perches and string on activity levels, fearfulness, and leg health in commercial broiler chickens. Animal, 9(4), 660-668. https://doi.org/10.1017/S1751731114002821

Bailie, C. L., Baxter, M., \& O’Connell, N. E. (2018). Exploring perch provision options for commercial broiler chickens. Appl. Animal Behav. Sci., 200, 114-122. https://doi.org/10.1016/j.applanim.2017.12.007
Bizeray, D., Estevez, I., Leterrier, C., \& Faure, J. M. (2002). Effects of increasing environmental complexity on the physical activity of broiler chickens. Appl. Animal Behav. Sci., 79(1), 27-41. https://doi.org/10.1016/S0168-1591(02)00083-7

Carr, L. E., Wheaton, F. W., \& Douglass, L. W. (1990). Empirical models to determine ammonia concentrations from broiler chicken litter. Trans. ASAE, 33(4), 1337-1342. https://doi.org/10.13031/2013.31478

Chai, L., Xin, H., Zhao, Y., Wang, T., Soupir, M., \& Liu, K. (2018). Mitigating ammonia and PM generation of cage-free henhouse litter with solid additive and liquid spray. Trans. ASABE, 61(1), 287-294. https://doi.org/10.13031/trans.12481

Cheal, M. (1987). Environmental enrichment facilitates foraging behavior. Physiol. Behav., 39(2), 281-283. https://doi.org/10.1016/0031-9384(87)90023-0

Dozier III, W. A., Kidd, M. T., Corzo, A., Anderson, J., \& Branton, S. L. (2007). Dietary amino acid responses of mixed-sex broiler chickens from two to four kilograms. J. Appl. Poultry Res., 16(3), 331-343. https://doi.org/10.1093/japr/16.3.331

Dunlop, M. W., Moss, A. F., Groves, P. J., Wilkinson, S. J., Stuetz, R. M., \& Selle, P. H. (2016). The multidimensional causal factors of 'wet litter' in chicken-meat production. Sci. Total Environ., 562, 766-776.

https://doi.org/10.1016/j.scitotenv.2016.03.147

Edwards Jr., H. M., \& Sorensen, P. (1987). Effect of short fasts on the development of tibial dyschondroplasia in chickens. $J$. Nutrition, 117(1), 194-200. https://doi.org/10.1093/jn/117.1.194

Elliott, H. A., \& Collins, N. E. (1982). Factors affecting ammonia release in broiler houses. Trans. ASAE, 25(2), 413-418. https://doi.org/10.13031/2013.33545

Federici, J. F., Vanderhasselt, R., Sans, E. C., Tuyttens, F. A., Souza, A. P., \& Molento, C. F. (2016). Assessment of broiler chicken welfare in southern Brazil. Brazilian J. Poultry Sci., 18, 133-140. https://doi.org/10.1590/18069061-2015-0022

Haslam, S. M., Knowles, T. G., Brown, S. N., Wilkins, L. J., Kestin, S. C., Warriss, P. D., \& Nicol, C. J. (2007). Factors affecting the prevalence of foot pad dermatitis, hock burn, and breast burn in broiler chicken. British Poultry Sci., 48(3), 264-275. https://doi.org/10.1080/00071660701371341

Herreid II, C. F., \& Kessel, B. (1967). Thermal conductance in birds and mammals. Comp. Biochem. Physiol., 21(2), 405-414. https://doi.org/10.1016/0010-406X(67)90802-X

Jong, I. C. De, Gunnink, H., \& van Harn, J. (2014). Wet litter not only induces footpad dermatitis but also reduces overall welfare, technical performance, and carcass yield in broiler chickens. $J$. Appl. Poultry Res., 23(1), 51-58. https://doi.org/10.3382/japr.2013-00803

Kaukonen, E., Norring, M., \& Valros, A. (2017). Perches and elevated platforms in commercial broiler farms: Use and effect on walking ability, incidence of tibial dyschondroplasia, and bone mineral content. Animal, 11(5), 864-871. https://doi.org/10.1017/S1751731116002160

Kestin, S. C., Knowles, T. G., Tinch, A. E., \& Gregory, N. G. (1992). Prevalence of leg weakness in broiler chickens and its relationship with genotype. Vet. Rec., 131(9), 190-194. https://doi.org/10.1136/vr.131.9.190

Knowles, T. G., Kestin, S. C., Haslam, S. M., Brown, S. N., Green, L. E., Butterworth, A., ... Nicol, C. J. (2008). Leg disorders in broiler chickens: Prevalence, risk factors, and prevention. PLoS One, 3(2), e1545. https://doi.org/10.1371/journal.pone.0001545

Kristensen, H. H., \& Wathes, C. M. (2000). Ammonia and poultry welfare: A review. World's Poultry Sci. J., 56(3), 235-245. https://doi.org/10.1079/WPS20000018

Kyvsgaard, N. C., Jensen, H. B., Ambrosen, T., \& Toft, N. (2013). Temporal changes and risk factors for foot-pad dermatitis in 
Danish broilers. Poultry Sci., 92(1), 26-32. https://doi.org/10.3382/ps.2012-02433

Leeson, S., \& Walsh, T. (2004). Feathering in commercial poultry: II. Factors influencing feather growth and feather loss. World's Poultry Sci. J., 60(1), 52-63. https://doi.org/10.1079/WPS20034

Liu, Z., Wang, L., Beasley, D., \& Oviedo, E. (2007). Effect of moisture content on ammonia emissions from broiler litter: A laboratory study. J. Atmos. Chem., 58(1), 41-53. https://doi.org/10.1007/s10874-007-9076-8

Martland, M. F. (1985). Ulcerative dermatitis dm broiler chickens: The effects of wet litter. Avian Pathol., 14(3), 353-364. https://doi.org/10.1080/03079458508436237

Miles, D. M., Branton, S. L., \& Lott, B. D. (2004). Atmospheric ammonia is detrimental to the performance of modern commercial broilers. Poultry Sci., 83(10), 1650-1654. https://doi.org/10.1093/ps/83.10.1650

Moore Jr., P. A., Daniel, T. C., \& Edwards, D. R. (1999). Reducing phosphorus runoff and improving poultry production with alum. Poultry Sci., 78(5), 692-698. https://doi.org/10.1093/ps/78.5.692

Nakaue, H. S., Koelliker, J. K., \& Pierson, M. L. (1981). Studies with clinoptilolite in poultry: II. Effect of feeding broilers and the direct application of clinoptilolite (zeolite) on clean and reused broiler litter on broiler performance and house environment. Poultry Sci., 60(6), 1221-1228. https://doi.org/10.3382/ps.0601221

NIOSH. (2005). NIOSH pocket guide to chemical hazards. Washington, DC: NIOSH. Retrieved from https://www.cdc.gov/niosh/docs/2005-149/pdfs/2005-149.pdf

Norring, M., Kaukonen, E., \& Valros, A. (2016). The use of perches and platforms by broiler chickens. Appl. Animal Behav. Sci., 184, 91-96. https://doi.org/10.1016/j.applanim.2016.07.012

NRC. (1994). Nutrient requirements of poultry (9th Rev. Ed.). Washington, DC: National Research Council.

Olanrewaju, H. A., Miller, W. W., Maslin, W. R., Thaxton, J. P., Dozier III, W. A., Purswell, J., \& Branton, S. L. (2007). Interactive effects of ammonia and light intensity on ocular, fear, and leg health in broiler chickens. Intl. J. Poultry Sci., 6, 762769. https://doi.org/10.3923/ijps.2007.762.769

Parajuli, P., Huang, Y., Zhao, Y., Tabler, T., \& Purswell, J. L. (2018). Comparative evaluation of poultry avoidance distances to human vs. robotic vehicle. ASABE Paper No. ILES18142. St. Joseph, MI: ASABE. https://doi.org/10.13031/iles.18-142

Pettit-Riley, R., \& Estevez, I. (2001). Effects of density on perching behavior of broiler chickens. Appl. Animal Behav. Sci., 71(2), 127-140. https://doi.org/10.1016/S0168-1591(00)00174-X

Poultry Site. (2009). U.S. chicken feet kicked out of China. The Poultry Site (9 July 2009). Retrieved from http://www.thepoultrysite.com/poultrynews/18142/us-chickenfeet-kicked-out-of-china
Purswell, J. L., Olanrewaju, H. A., \& Linhoss, J. E. (2018). Effect of light intensity adjusted for species-specific spectral sensitivity on live performance and processing yield of male broiler chickens. J. Appl. Poultry Res., 27(4), 570-576. https://doi.org/10.3382/japr/pfy034

Quarles, C. L., \& Caveny, D. D. (1979). Effect of air contaminants on performance and quality of broilers. Poultry Sci., 58(3), 543548. https://doi.org/10.3382/ps.0580543

Reece, F. N., Lott, B. D., \& Deaton, J. W. (1981). Low concentrations of ammonia during brooding decrease broiler weight. Poultry Sci., 60(5), 937-940. https://doi.org/10.3382/ps.0600937

Rodriguez-Aurrekoetxea, A., Leone, E. H., \& Estevez, I. (2015). Effects of panels and perches on the behaviour of commercial slow-growing free-range meat chickens. Appl. Animal Behav. Sci., 165, 103-111. https://doi.org/10.1016/j.applanim.2015.02.004

Shepherd, E. M., \& Fairchild, B. D. (1987). Footpad dermatitis in poultry. Poultry Sci., 89(10), 2043-2051. https://doi.org/10.3382/ps.2010-00770

Sims, J. T., \& Wolf, D. C. (1994). Poultry waste management: Agricultural and environmental issues. In D. L. Sparks (Ed.), Advances in agronomy (Vol. 52, pp. 1-83). Cambridge, MA: Academic Press. https://doi.org/10.1016/S0065-2113(08)606215

Stephenson, E. L., Bezanson, J. M., \& Hall, C. F. (1960). Factors affecting the incidence and severity of a breast blister condition in broilers. Poultry Sci., 39(6), 1520-1524. https://doi.org/10.3382/ps.0391520

Stevenson, R., Dalton, H. A., \& Erasmus, M. (2019). Validity of micro-data loggers to determine walking activity of turkeys and effects on turkey gait. Front. Vet. Sci., 5(319).

https://doi.org/10.3389/fvets.2018.00319

Ventura, B. A., Siewerdt, F., \& Estevez, I. (2010). Effects of barrier perches and density on broiler leg health, fear, and performance. Poultry Sci., 89(8), 1574-1583. https://doi.org/10.3382/ps.200900576

Ventura, B. A., Siewerdt, F., \& Estevez, I. (2012). Access to barrier perches improves behavior repertoire in broilers. PLoS One, 7(1), e29826. https://doi.org/10.1371/journal.pone.0029826

Waldenstedt, L. (2006). Nutritional factors of importance for optimal leg health in broilers: A review. Animal Feed Sci. Tech., 126(3), 291-307. https://doi.org/10.1016/j.anifeedsci.2005.08.008

Welfare Quality. (2009). Welfare Quality, Assessment protocol for poultry (broilers, laying hens). Lelystad, Netherlands: Welfare Quality Consortium. 